\title{
Institutional Review Board
}

National Cancer Institute

\section{Source}

National Cancer Institute. Institutional Review Board. NCI Thesaurus. Code C16741.

A specially constituted independent review body comprised of medical, scientific and nonscientific members established and designated by an entity to ensure the protection of the rights, safety and well-being of human subjects recruited to participate in biomedical or behavioral research according to the requirements outlined in Title 38, part 16 (same as Title 45, part 46 and Title 21, part 56) of the U.S. Code of Federal Regulations. IRB responsibility include but not limited to the reviewing, approving, and providing continuing review of trial protocol and amendments and of the methods and material(s) to be used in obtaining and documenting informed consent of the trial. Other equivalent committees with the same or similar functions are also considered to be IRBS. 